\title{
Mike Curtis: 'It's criminal that we still have such high levels of childhood caries'
}

\author{
Interview by Ruth Doherty
}

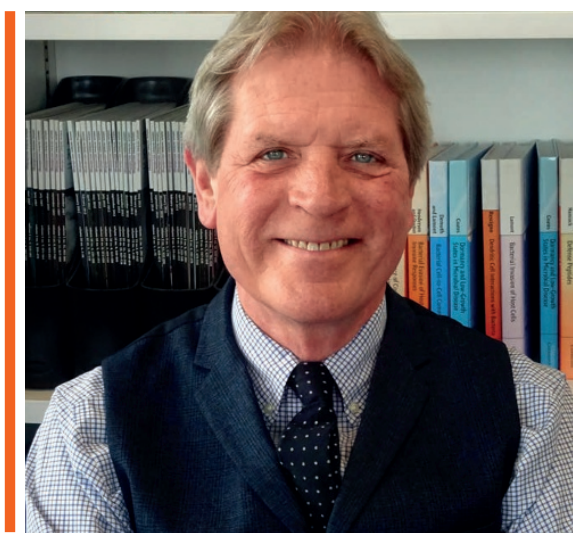

You're a microbiologist, how did you end up as Dean of a dental institute?

To start with I wasn't even a microbiologist! I actually studied biochemistry as a first degree at the University of Bristol.

In my final year project I did a study of metabolism in bacteria, and the source of that bacteria happened to be dental plaque - so rather than growing the bugs we just scraped them off teeth, and then did quite clever things with radiolabelled sugar and measured carbon dioxide and so on. Through that project, I got to know a dental academic, Mike Hayes in Bristol, and it just ran from there really. I then did a PhD looking at the chemical analysis of dental plaque with John Eastoe at the Royal College of Surgeons in Lincoln's Inn Fields.

During this time, I met more and more people from the world of dentistry including one guy called William Bowen, who had just been appointed Chief of the National Caries Programme in the US, which incidentally had been set up by Richard Nixon, when he 'waged war on caries'. After my PhD, Bill Bowen invited me to work with him at the National Institute of Dental Research in Washington, and I spent five very happy years there. So along the way I transformed myself from a biochemist into a

\section{Professor Mike Curtis is the new Executive Dean of King's College London} Dental Institute. He moved to King's from his former position as Dean of Dentistry and Deputy Vice-Principal (Health) at Barts and The London School of Medicine and Dentistry, QMUL. Mike is a microbiologist and his research is focused on the role of the oral microbiome in maintaining oral health and developing disease, and key microbial virulence determinants of oral bacteria. He is a former President of the British Society for Oral and Dental Research, and he delivered the 2016 BDA/BDJ Winter Lecture.

microbiologist and my whole career has been around dental research.

Sometimes students do ask how I am a dental dean even though I'm not a dentist. And I ask them 'What do you think a dental dean does?' I explain that my role is mainly about setting strategy, creating the right environment for them to learn and research, and basically getting everybody lined up together and marching down the road. I don't need to practise dentistry and I use the same skills as you would in any academic leadership role.

My background in biochemistry really helps. Biochemistry is a study of how life works at a molecular level and you can understand all sorts of different areas with it. So it's not that difficult for me to now understand cellular formation, how enamel crystallises or how bone gets resorbed because they are all basically biochemical processes. It's a subject that crosses all sorts of different domains.

\section{What are the challenges facing dental students graduating today?}

I think the way higher education has gone over the last ten years means that all students have financial pressures they didn't have previously, and for those doing longer clinical courses even more so because they have five years of undergraduate existence to survive.

Professionally, the practice of both clinical medicine and dentistry is fast moving and keeping pace with the changes is not straightforward, albeit exciting.

One of the obligations we have in any dental school is to prepare our students for those challenges in the best way we can - so tutoring them in the management of their own financial resources and of their own health and work-life balance is important. All of those issues are central to how they are going to survive when they finally fly the coop and are out in the big, wide world.

You go to student support offices around the country and every single one of them will report massive increases in mental health problems across the university. I don't know why this is but I expect that there is a lot of expectation on students now, possibly linked to the fee structure.

We have the responsibility to take care of the students and it's important for us, as staff, to participate in student-staff liaison committees and to make ourselves available to dental students. Though we mightn't be able to change anything at least the students will then know that we are listening to them and that the school as a whole is aware of their problems. 


\section{What do you hope to achieve in your new position at $\mathrm{KCL}$ ?}

It's a big organisation - the largest dental school in the UK - and it's a complicated environment because it's part of a multifaculty university and it interfaces with two separate NHS Trusts. I'm a great believer in understanding where an organisation has been before planning on where it's going to go next so that's what I'm doing at the moment. There's also a legacy from the previous deans that's ready to build on.

There are so many opportunities: to rebuild some of the estate and to build an even better research profile; to lead on dental education in the UK; and to expand the educational offering at all levels.

\section{What are you most proud of?}

One of the projects I don't get to talk about very much is a public engagement project I initiated when I was Director of the Blizard Institute of Cell and Molecular Science (before I moved to the School of Dentistry at Barts). We wanted to say to the kids of the East End of London - you can be a dentist, or a doctor or a nurse or a biomedical scientist, so we created a science centre for school children. It is less about understanding science and more about raising their aspirations.

It's called the Centre of the Cell and it's based in a big orange, multi-lobed pod suspended over the main laboratories in the Blizard Building in Whitechapel. It has lots of high tech games for the children to play, like the poo racer where they get to chase a poo down the intestinal tract and games allowing them to explore a cell etc.

\section{We have seen much debate recently about dental education in the UK and whether or not it prepares students adequately for real clinical practice. What are your thoughts?}

I think it's a hugely controversial area and we've had some discussions at Dental Schools Council on this. The way I read it is that the data are controversial. There are some studies suggesting that there has been a high level of dissatisfaction amongst the trainers but then on the counter side a 2016 survey of FT1s showed that $90 \%$ of them felt they were prepared for the FT year. There is a danger of a knee-jerk reaction on this which would mean we introduce national numerical system of competency assessment, for example, every student must perform a certain number of crowns, but I think that this could be unworkable.

First, I don't believe all Schools could do it because of patient flows. Second, I don't think it's a good measure of competency. I think our job in dental schools is to produce a safe beginner who is fully compliant with the GDC principles. And that is what we do.

What you hope is that you have made your students safe and competent beginners, but also that you have made them individuals who are capable of developing and willing to understand the value of life-long learning. My personal view is that dental education in the UK is very good. It's a privilege to be around these enthusiastic and capable dental students - some of the brightest and most able young people in our society.

One of the difficulties is that most Schools train their students in hospitals using

\section{'It's a privilege to be around these enthusiastic and capable dental students - some of the brightest and most able young people in our society...'}

I didn't do the heavy lifting around setting it up but I was in the background and it was my idea. I was always there to help but the people who led it were fantastic. It took quite a few years to get the centre up and running, and it needed a lot of money because it had its own dedicated space. They have just had about 150,000 kids through it now and I still feel a tinge of pride when I see a class of school kids queuing up to go. They have just got funding to build a second pod shaped like a neuron cell (it's going to look more like a spikey hedgehog!). patients that are referred from primary care because those patients are considered beyond the scope of primary care. This is why the development of outreach clinics for undergraduate education have proved so popular and successful. Another problem for us is that when the students leave here they are going into a myriad of different environments all over the country. It would be impossible for us to prepare students for every single eventuality or practice that they are going to encounter, so our job is to make them safe beginners able to absorb further development and be flexible.

\section{KCL has an active 'Women in Dentistry' group who point out that women are underrepresented in most specialties and in leadership positions in dentistry, what do you think might help to generate equality in these areas?}

The intake of dental students now has a higher proportion of women than men but when you look around dental leadership, eg the Dental Schools Council table (2 women out of 16), you can see the inequality. Ultimately, it's about fairness, not just gender fairness but fairness in every aspect.

There are particular issues around women, for example, career breaks are the ones that are highlighted the most. I think there are things we can do to mitigate the impact a career break may have on someone's ability to progress through the promotional ranks and we are introducing these. Initiatives in universities, like Athena Swan, have been really important for that - the way that programme was linked to financial penalties was very important, at least in the early stages, because it got it absolutely front and centre in people's minds that this was imperative. Regardless of the moral imperative there was a financial imperative there too.

Initiatives such as having a proper, structured return to work with support for those returning from parental leave are helpful, as is getting support for gender balance on committees, particularly recruitment committees, and executive teams.

It's also important to introduce more junior staff to senior management processes so there isn't a hoodoo around them. Some of this is around confidence, and I think that just exposing how the machinery works at senior management level can soon dispel any feelings about being unable to perform at that level. There are a number of things we could do to help generate more equality and we are increasingly doing it but it's going to take a long time.

Your research focusses on oral bacteria and the oral microbiome, what have you most enjoyed finding out about and has anything surprised you?

You get a satisfaction from breaking down a process and discovering how the key components work, and then piecing it back together again as a working system. For

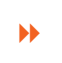


14 many years my group worked on the bacterial factors we thought were important for periodontal disease. So we took bacteria and pulled them apart biochemically and took them apart genetically, and we'd knock out genes and test them, and eventually you build up a picture. Essentially you've created a landscape of understanding and if you do it for long enough you just fill in more of the detail. I'm quite proud of all of that area (basic microbial biology and virulence) and that is what the group is best known for.

The oral microbiome work has come along more recently in between the last 5-10 years. In terms of the most surprising result, we showed that if you take an organism thought to be involved in perio disease and you infect green veg etc. When you ingest the nitrate it goes into the circulation and is concentrated in your saliva. It gets acted upon by bacteria in the mouth and they reduce it from nitrate to nitrite. [This is very unusual - we don't have any enzymes that can do that ourselves; only the bacteria can do that.] Then the nitrite in the mouth gets swallowed and goes into the stomach, and the acid conditions in the stomach change the nitrite into nitric oxide which is a gas, important for regulating blood pressure. So if you eat a lot of nitratecontaining foods they can lower your blood pressure, and if you interrupt this system, for example by spitting in a bucket for a couple of hours, your blood pressure goes up because you've broken the cycle.

\section{'As recently as 20 years ago a $\mathrm{PhD}$ could involve finding a gene and sequencing it and that was the entire thesis. Now that is 30 seconds work.'}

a mouse with that organism, then the mouse develops periodontal bone loss. But if you take a germ-free mouse (with no bacteria) and infect that with the same organism then it doesn't get any perio bone loss. The reason is that the normal bacteria are fundamentally important to driving the disease so if you don't have the normal bacteria there then having the perio pathogen is irrelevant.

It's a cycle - the bacteria respond to environmental changes, so when inflammation comes along the bacteria change in proportions and activities and this in turn leads to a heightened level of inflammation. In most people this cycle is controlled - there are sufficient checks and balances in the tissues to maintain a healthy homeostasis - but in some people, for reasons we don't really fully understand, that balance becomes tipped in favour of a disease process.

I collaborate with a group who are working on the enteric nitrate cycle. They are looking at foods that contain nitrate, eg beetroot,
So the project we are working on is to see whether you can use nitrate as a public health measure for controlling blood pressure in the population. And one of the things that has been shown is that a variety of mouthwashes have an impact on blood pressure (a transient effect only!) because by knocking the bugs out in the mouth they interrupt the nitrate cycle. This was an interesting finding!

\section{Are there any particular technologies that have helped to advance your research in the last ten years?}

The genetics revolution has helped considerably. As recently as twenty years ago a $\mathrm{PhD}$ project could involve finding a gene and sequencing it and that was the entire thesis. Now that is 30 seconds work. We have now sequenced all the organisms we work with so if you're interested in a gene you just type it in and there you go along with the context of all the other genes around it and what is known about the mutants that have been made.
This is the same for every area of biology. This genetics revolution has made things easier, speeded things up and allows you to spend more time asking the questions.

\section{What questions would you like dental research to find answers to in the next ten years?}

I believe it's criminal that we still have such high levels of childhood caries. For a preventable disease, it's just unacceptable that one of the main reasons that children are admitted to hospital is to have their teeth extracted. I'm very supportive of the multi-faceted initiatives that are around now for developing strategies to impact on childhood caries - behavioural change, the sugar lobby and all of those things need to come together and that will make such a difference.

Another would be getting a better understanding of oral health and disease and the connections to general health. For example, we need to learn how great is the influence of oral health on cardiovascular disease, diabetes, different forms of cancer, pregnancy complications and so on. We haven't yet nailed it.

We have some catch-all mechanisms, eg 'it's all about inflammation', but I doubt that's quite it. I suspect there are a number of different mechanisms at work linking between the different conditions. There will be some that have no links and are just associations but even that's important to know, because it will be incredibly useful if you can look in someone's mouth and predict the state of their health.

\section{What historical item do you wish you had invented?}

The telescope. I'm fascinated by our solar system and also what lies beyond that in different galaxies across the universe. I think it's a fascinating area and over the years the individuals who have perfected ways of looking at the stars in greater and greater levels of detail are fantastic. One day we will find life out there and to have been part of that journey would be wonderful. 